\title{
Positive association of Parkinson's disease with ankylosing spondylitis: a nationwide population-based study
}

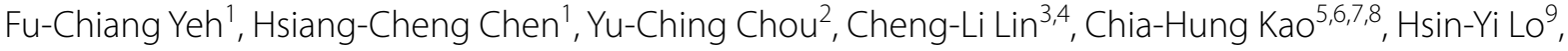
Feng-Cheng Liu ${ }^{1 *+}$ and Tse-Yen Yang $8,10,11,12^{*+}$ (D)

\begin{abstract}
Background: Ankylosing spondylitis (AS) is characterized by excessive production of inflammatory cytokines. Recent evidence suggests that inflammation underlies the neurodegenerative process of Parkinson's disease (PD). Whether AS has an influence on the development of PD is unclear. We aimed to examine a relationship, if any exists between AS and PD.

Methods: A population-based matched cohort study was performed using data from the 2000-2010 Taiwan National Health Insurance database. 6440 patients with AS and 25,760 randomly selected, age- and sex-matched controls were included in this study. The risk of PD in the AS cohort was evaluated by using a Cox model.

Results: This study revealed a positive association between AS and the risk of PD regardless of sex and age (aHR 1.75, $p<.001)$. Particularly, AS cohort to non-AS cohort relative risk of PD significantly increased for the patients aged below 49 and above 65 years (aHR 4.70, $p<.001$; aHR 1.69, $p<.001$, respectively) and the patients with and without comorbidities (aHR 1.61, $p<.001$; aHR 2.71, $p<.001$, respectively). Furthermore, NSAID use was associated with lower risk of PD (aHR 0.69, $p<.05$ ). However, the risk of PD was higher (aHR 2.40, $p<.01$ ) in patients with AS receiving immunosuppressants than in those not receiving (aHR 1.70, $p<.001$ ).
\end{abstract}

Conclusions: Patients with AS had an increased risk of PD which might be related to underlying chronic inflammation. Further research is required to elucidate the underlying mechanism.

Keywords: Ankylosing spondylitis (AS), Parkinson's disease (PD), Immunology, National health insurance research database (NHIRD), Retrospective cohort

\section{Background}

Ankylosing spondylitis (AS) is an autoimmune, chronic inflammatory rheumatic disorder that mainly affects the axial skeleton, peripheral joints and entheses,

\footnotetext{
*Correspondence: Ifc10399@yahoo.com.tw; yang_t_y@yahoo.com.tw

${ }^{\dagger}$ Feng-Cheng Liu and Tse-Yen Yang contributed equally

${ }^{1}$ Division of Rheumatology, Immunology, and Allergy, Department

of Internal Medicine, Tri-Service General Hospital, National Defense Medical Center, Taipei, Taiwan

${ }^{8}$ Center of Augmented Intelligence in Healthcare, China Medical University Hospital, Taichung, Taiwan

Full list of author information is available at the end of the article
}

causing severe chronic pain [1]. The development of AS is strongly associated with increased production of tumor necrosis factor-a (TNF-a), interleukin-6 (IL-6) and interleukin-17 (IL-17) [2, 3]. Extra-articular manifestations of AS caused by chronic inflammation, including uveitis, inflammatory bowel disease, osteoporosis, glomerulonephritis and cardiopulmonary involvement, vary widely in terms of frequency and severity [4]. Studies have shown that AS is associated with increased risk of depression, dementia and ischemic stroke; [5-7] however, the

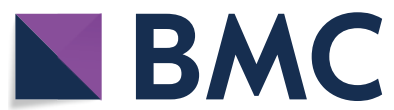

(c) The Author(s) 2020. This article is licensed under a Creative Commons Attribution 4.0 International License, which permits use, sharing, adaptation, distribution and reproduction in any medium or format, as long as you give appropriate credit to the original author(s) and the source, provide a link to the Creative Commons licence, and indicate if changes were made. The images or other third party material in this article are included in the article's Creative Commons licence, unless indicated otherwise in a credit line to the material. If material is not included in the article's Creative Commons licence and your intended use is not permitted by statutory regulation or exceeds the permitted use, you will need to obtain permission directly from the copyright holder. To view a copy of this licence, visit http://creativeco mmons.org/licenses/by/4.0/. The Creative Commons Public Domain Dedication waiver (http://creativecommons.org/publicdomain/ zero/1.0/) applies to the data made available in this article, unless otherwise stated in a credit line to the data. 
underlying mechanism of central nervous system (CNS) involvement in AS is still unknown.

Parkinson's disease (PD), a common neurodegenerative disorder of the CNS causing bradykinesia, resting tremor, postural instability and muscle rigidity, is pathologically due to progressive cell death of dopaminergic neurons located in the substantia nigra pars compacta [8]. The etiology of PD is multifactorial, however, there is an increasing emphasis that inflammation underlies the neurodegenerative process. Dysfunction of the immune system, such as autoimmune response, may involve in the pathogenesis of the disease. [9] Pro-inflammatory cytokines, specifically TNF-a and IL-6, are significantly increased in the serum and cerebrospinal fluid of PD patients [10-15]. Furthermore, recent studies revealed that serum IL-6 and IL-17 positively correlate with severity of symptoms in PD $[12,14]$. The relationship between PD and autoimmune diseases that chronically produce high concentrations of inflammatory cytokines has been reported [16, 17]. However, whether AS is associated with the generation of PD is yet unclear.

In current study, we hypothesized that AS patients are at higher risk of developing PD and we aimed to determine the risk of PD in patients with AS and to identify the associated risk factors by conducting a nationwide longitudinal population-based matched cohort study.

\section{Methods}

\section{Data Source}

This nationwide cohort study was performed by using data from Taiwan's Longitudinal Health Insurance Database 2000 (LHID2000). The LHID2000 includes all claims data of a million individuals randomly sampled from the 2000 registry for beneficiaries of the National Health Insurance Research Database (NHIRD) [18]. The Taiwanese government established the National Health Insurance (NHI) program in 1995. This single-payer health insurance program enrolled more than $99 \%$ of the entire population of 23.74 million people in Taiwan (http://www.nhi.gov.tw/english/index.aspx). Details of the NHI program are described in previous studies $[19,20]$. According to the Personal Information Protection Act, the records of patients were de-identified and all researchers signed their agreement for not obtaining privacy of the patients. This study was approved by the Institutional Review Board of China Medical University (CMUH-104-REC2-115).

\section{Study population}

The ankylosing spondylitis (AS) cohort included newly diagnosed AS (ICD-9-CM code 720) patients from 2000 to 2010. The index date for each case was defined as the date of AS diagnosis. According to the age (5-year span), sex, and index year, four non-AS controls were randomly selected from the LHID2000 and frequency-matched to each AS patient. The index date for a non-AS control was assigned as the same as the matched AS patient. Patients with history of PD (ICD-9-CM code 332) before index date were excluded from both cohorts (Table 1).

\section{Outcome, comorbidity and medication}

Both cohorts were followed up from the index date until the PD onset date, December 31, 2011 or withdrawal from the NHI program, whichever came first. Age of the patient was divided into 5-year categories, and the groups were merged when necessary. Baseline comorbidities including diabetes (ICD-9-CM code 250), hyperlipidemia (ICD-9-CM code 272), hypertension (ICD-9-CM codes 401 to 405), stroke (ICD-9-CM codes 430 to 438), depression (ICD-9-CM codes 296.2, 296.3, 300.4, 311),

Table 1 Demographic characteristics and co-morbidity in patients with and without ankylosing spondylitis

\begin{tabular}{|c|c|c|c|c|c|}
\hline \multirow[t]{3}{*}{ Variables } & \multicolumn{4}{|c|}{ Ankylosing spondylitis } & \multirow[t]{3}{*}{$p$ value } \\
\hline & \multicolumn{2}{|c|}{$\begin{array}{l}\text { No } \\
(N=25,760) \\
\end{array}$} & \multicolumn{2}{|c|}{$\begin{array}{l}\text { Yes } \\
(N=6440)\end{array}$} & \\
\hline & $\mathrm{n}$ & $\%$ & $\mathrm{n}$ & $\%$ & \\
\hline Sex & & & & & 0.99 \\
\hline Male & 12,396 & 48.1 & 3099 & 48.1 & \\
\hline Female & 13,364 & 51.9 & 3341 & 51.9 & \\
\hline Age, years & & & & & 0.99 \\
\hline $20-34$ & 6976 & 27.1 & 1744 & 27.1 & \\
\hline $35-49$ & 7588 & 29.5 & 1897 & 29.5 & \\
\hline $50-64$ & 6592 & 25.6 & 1648 & 25.6 & \\
\hline$\geq 65$ & 4604 & 17.9 & 1151 & 17.9 & \\
\hline Mean $(\mathrm{SD})^{\dagger}$ & 47.3 & 17.1 & 47.6 & 16.9 & 0.15 \\
\hline \multicolumn{6}{|l|}{ Comorbidity } \\
\hline Diabetes & 1734 & 6.73 & 497 & 7.72 & 0.01 \\
\hline Hypertension & 6032 & 23.4 & 1874 & 29.1 & $<0.001$ \\
\hline Hyperlipidemia & 3857 & 15.0 & 1348 & 20.9 & $<0.001$ \\
\hline Stroke & 661 & 2.57 & 167 & 2.59 & 0.90 \\
\hline Depression & 868 & 3.37 & 375 & 5.82 & $<0.001$ \\
\hline Coronary artery disease & 2869 & 11.1 & 1054 & 16.4 & $<0.001$ \\
\hline Head injury & 599 & 2.33 & 209 & 3.25 & $<0.001$ \\
\hline Chronic kidney disease & 1368 & 5.31 & 532 & 8.26 & $<0.001$ \\
\hline Epilepsy & 164 & 0.64 & 43 & 0.67 & 0.78 \\
\hline \multicolumn{6}{|l|}{ Medication } \\
\hline NSAIDs & 6053 & 23.5 & 1591 & 24.7 & 0.04 \\
\hline Immunosuppressant therapy & & & 1282 & 19.9 & \\
\hline Biological therapy & & & 37 & 0.57 & \\
\hline
\end{tabular}

Case group mean follow-up 6.72(SD = 3.29)

Control group mean follow-up 6.63(SD = 3.31)

Chi-square test; ${ }^{\dagger}$ Two sample t-test 
head injury (ICD-9-CM codes 850 to $854,959.01$ ), coronary artery disease (CAD) (ICD-9-CM codes 410 to 414), chronic kidney disease (ICD-9-CM codes 580 to 589) and epilepsy (ICD-9-CM code 345) considered as risk factors of PD were also analyzed [21]. In addition, the use of nonsteroidal anti-inflammatory drugs (NSAIDs), immunosuppressants (sulfalsalazine and methotrexate) and various biological agents (including adalimumab, golimumab, and etanercept) were analyzed between the two cohorts.

\section{Statistical analysis}

The chi-square test was used to compare descriptive statistics on demographic status, baseline comorbidities and medication between AS and non-AS cohorts. Student $t$ test was used to compare the AS and non-AS cohorts for continuous variables. The Kaplan-Meier method was used to estimate the cumulative incidence of PD in the AS and non-AS cohorts, and the difference was tested using a log-rank test (Fig. 1). The incidence density rates (per 1000 person-years) for PD were calculated. Univariate and multivariate Cox proportional hazards regression analyses were used to calculate the hazard ratios (HRs) with stratification according to sex, age, and comorbidity. The multivariate Cox models were simultaneously adjusted for age and comorbidities of diabetes, hypertension, hyperlipidemia, stroke, depression, coronary artery disease, head injury and chronic kidney disease and

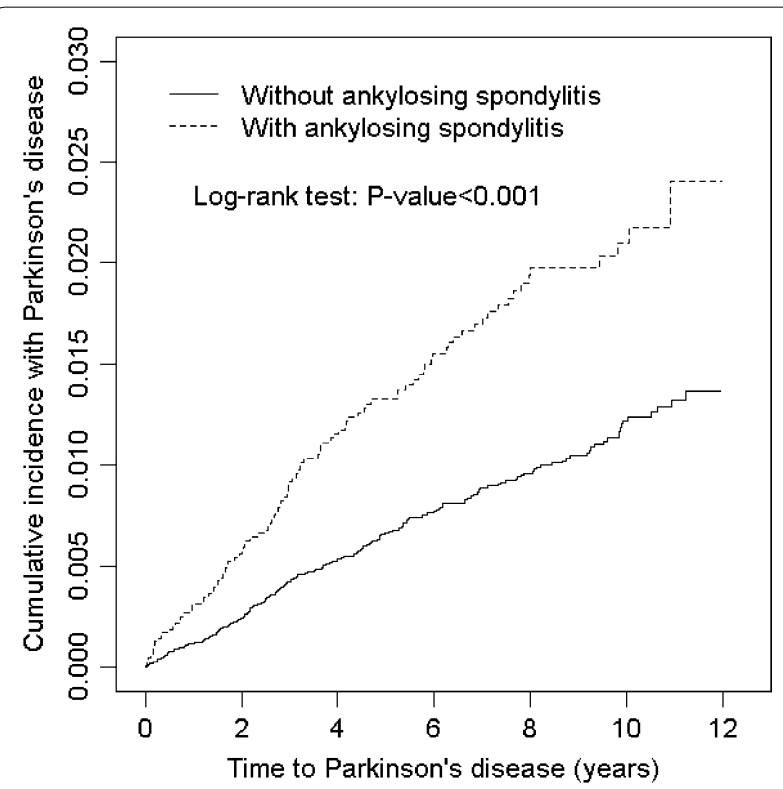

Fig. 1 Comparison of cumulative incidence of Parkinson disease between patients with and without ankylosing spondylitis. The Kaplan-Meier plot showed that the AS cohort had a higher cumulative incidence of PD than the non-AS cohort did (log-rank test, $p<.001)$ medication of NSAIDs. Furthermore, we evaluated the treatment effect of immunosuppressants and biological agents on the risk of Parkinson's disease in the AS cohort. All statistical analyses were conducted using SAS 9.4 software (SAS Institute, Cary, NC, USA). A two-tailed $p$ value $<0.05$ was considered statistically significant.

\section{Results}

This study included 6440 AS patients and 25,760 non-AS patients with similar age and sex distributions (Table 1). In both cohorts, $51.9 \%$ patients were women. The mean age of the patients was approximately 47 years old and $56.6 \%$ of the patients were younger than 49 years of age. Comorbidities of diabetes, hypertension, hyperlipidemia, depression, coronary artery disease, head injury, chronic kidney disease, and use of NSAIDs were more prevalent in the AS cohort than in the non-AS cohort (all $p<0.05$ ). The mean follow-up period was 6.72 years in the AS cohort and 6.63 years in the non-AS cohort. The Kaplan-Meier analysis showed that the cumulative incidence of Parkinson's disease was significantly higher in the AS cohort than in the non-AS cohort (log-rank test, $p<0.0001$ ) (Fig. 1).

The overall incidence of $\mathrm{PD}$ was greater in the AS cohort than in the non-AS cohort with the incidence rates being 2.36 and 1.23 per 1000 person-years, respectively, yielding a crude HR of 1.92 (95\% CI 1.52-2.43, $p<0.001)$ and an aHR of 1.75 (95\% CI $1.38-2.22$, $p<0.001$ ) (Table 2). Compared with patients younger than 49 years old, elder patients had higher risk of developing PD (50-64 years, aHR 5.16; 95\% CI 3.23$8.23, p<0.001 ; \geq 65$ years, aHR 21.2 ; $95 \%$ CI $13.5-33.3$, $p<0.001)$. The multivariable analysis also demonstrated that PD was independently associated with comorbidities such as hypertension (aHR 1.39; 95\% CI 1.05-1.84, $p<0.05$ ), stroke (aHR 1.68; 95\% CI 1.16-2.43, $p<0.01$ ), and depression (aHR 1.97; 95\% CI 1.36-2.85, $p<0.001$ ). In contrast, the risk of PD was lower in patients taking NSAIDs compared with patients not taking (aHR 0.69; 95\% CI 0.50-0.96, $p<0.05)$.

The sex-specific AS cohort to non-AS cohort relative risk of PD was significantly higher for both women (aHR 1.66; 95\% CI 1.19-2.32, $p<0.001)$ and men (aHR 1.85; 95\% CI 1.31-2.62, $p<0.01$ ) (Table 3). The PD incidence increased with age, however, the age-specific AS cohort to non-AS cohort relative risk of PD was the highest for the group aged below 49 years (aHR 4.70; 95\% CI 2.10 $10.5, p<0.001$ ) followed by the group aged above 65 years (aHR 1.69; 95\% CI 1.26-2.26, $p<0.001$ ). In addition, the comorbidity-specific AS cohort to non-AS cohort relative risk of PD was significant higher both for patients with comorbidity (aHR 1.61; 95\% CI 1.23-2.10, $p<0.001$ ) 
Table 2 Incidence and Hazard ratio for Parkinson's disease and Parkinson's disease-associated risk factor

\begin{tabular}{|c|c|c|c|c|c|}
\hline Variable & Event & PY & Rate $^{\#}$ & $\begin{array}{l}\text { Crude HR(95\% } \\
\text { Cl) }\end{array}$ & $\begin{array}{l}\text { Adjusted } \mathrm{HR}^{\dagger} \\
(95 \% \mathrm{Cl})\end{array}$ \\
\hline \multicolumn{6}{|c|}{ Ankylosing spondylitis } \\
\hline No & 210 & 170,858 & 1.23 & 1.00 & 1.00 \\
\hline Yes & 102 & 43,252 & 2.36 & $\begin{array}{r}1.92(1.52 \\
2.43)^{* * *}\end{array}$ & $\begin{array}{r}1.75(1.38 \\
2.22)^{* * *}\end{array}$ \\
\hline \multicolumn{6}{|l|}{ Age, year } \\
\hline$\leq 49$ & 25 & 125,771 & 0.20 & 1.00 & 1.00 \\
\hline $50-64$ & 71 & 55,426 & 1.28 & $\begin{array}{r}6.44(4.08 \\
10.2)^{* * *}\end{array}$ & $\begin{array}{r}5.16(3.23 \\
8.23)^{* * *}\end{array}$ \\
\hline$\geq 65$ & 216 & 32,913 & 6.56 & $\begin{array}{r}32.7(21.6 \\
49.5)^{* * *}\end{array}$ & $\begin{array}{r}21.2(13.5 \\
33.3)^{* * *}\end{array}$ \\
\hline \multicolumn{6}{|l|}{ Sex } \\
\hline Female & 163 & 103,378 & 1.58 & 1.00 & 1.00 \\
\hline Male & 149 & 110,732 & 1.35 & $0.85(0.68,1.06)$ & - \\
\hline \multicolumn{6}{|c|}{ Comorbidity } \\
\hline \multicolumn{6}{|c|}{ Diabetes } \\
\hline No & 269 & 201,713 & 1.33 & 1.00 & 1.00 \\
\hline Yes & 43 & 12,397 & 3.47 & $\begin{array}{r}2.55(1.85 \\
3.52)^{* * *}\end{array}$ & $0.87(0.62,1.21)$ \\
\hline \multicolumn{6}{|c|}{ Hypertension } \\
\hline No & 111 & 165,512 & 0.67 & 1.00 & 1.00 \\
\hline Yes & 201 & 48,597 & 4.14 & $\begin{array}{r}6.12(4.85 \\
7.72)^{* * *}\end{array}$ & $1.39(1.05,1.84)^{*}$ \\
\hline \multicolumn{6}{|c|}{ Hyperlipidemia } \\
\hline No & 204 & 181,940 & 1.12 & 1.00 & 1.00 \\
\hline Yes & 108 & 32,169 & 3.36 & $\begin{array}{r}2.97(2.35 \\
3.75)^{* * *}\end{array}$ & $1.07(0.83,1.38)$ \\
\hline \multicolumn{6}{|l|}{ Stroke } \\
\hline No & 277 & 210,265 & 1.32 & 1.00 & 1.00 \\
\hline Yes & 35 & 3845 & 9.10 & $\begin{array}{r}6.73(4.73 \\
9.57)^{* * *}\end{array}$ & $1.68(1.16,2.43)^{* *}$ \\
\hline \multicolumn{6}{|c|}{ Depression } \\
\hline No & 279 & 207,215 & 1.35 & 1.00 & 1.00 \\
\hline Yes & 33 & 6895 & 4.79 & $\begin{array}{r}3.48(2.43 \\
5.00)^{* * *}\end{array}$ & $\begin{array}{l}1.97(1.36 \\
2.85)^{* * *}\end{array}$ \\
\hline \multicolumn{6}{|c|}{ Coronary artery disease } \\
\hline No & 190 & 190,490 & 1.00 & 1.00 & 1.00 \\
\hline Yes & 122 & 23,620 & 5.17 & $\begin{array}{c}5.13(4.09 \\
6.45)^{* * *}\end{array}$ & $1.28(0.99,1.65)$ \\
\hline \multicolumn{6}{|c|}{ Head injury } \\
\hline No & 298 & 209,730 & 1.42 & 1.00 & 1.00 \\
\hline Yes & 14 & 4379 & 3.20 & $\begin{array}{c}2.20(1.29, \\
3.76)^{* *}\end{array}$ & $1.28(0.74,2.20)$ \\
\hline \multicolumn{6}{|c|}{ Chronic kidney disease } \\
\hline No & 264 & 202,493 & 1.30 & 1.00 & 1.00 \\
\hline Yes & 48 & 11,617 & 4.13 & $\begin{array}{r}3.15(2.32 \\
4.28)^{* * *}\end{array}$ & $1.11(0.81,1.53)$ \\
\hline \multicolumn{6}{|l|}{ Epilepsy } \\
\hline No & 309 & 212,960 & 1.45 & 1.00 & 1.00 \\
\hline Yes & 3 & 1150 & 2.61 & $1.76(0.57,5.50)$ & - \\
\hline
\end{tabular}

Table 2 (continued)

\begin{tabular}{|c|c|c|c|c|c|}
\hline Variable & Event & PY & Rate $^{\#}$ & $\begin{array}{l}\text { Crude HR(95\% } \\
\text { Cl) }\end{array}$ & $\begin{array}{l}\text { Adjusted } \mathrm{HR}^{\dagger} \\
(95 \% \mathrm{Cl})\end{array}$ \\
\hline \multicolumn{6}{|c|}{ Medication } \\
\hline \multicolumn{6}{|c|}{ NSAIDs } \\
\hline No & 266 & 149,655 & 1.78 & 1.00 & 1.00 \\
\hline Yes & 46 & 64,455 & 0.71 & $\begin{array}{r}0.41(0.30 \\
0.56)^{* * *}\end{array}$ & $0.69(0.50,0.96)^{*}$ \\
\hline
\end{tabular}

Rate", incidence rate, per 1,000 person-years; Crude HR, relative hazard ratio; Adjusted $\mathrm{HR}^{\dagger}$ : multivariable analysis including age and comorbidities of diabetes, hypertension, hyperlipidemia, stroke, depression, coronary artery disease, head injury and chronic kidney disease and medication of NSAIDs ${ }^{*} p<0.05,{ }^{* *} p<0.01,{ }^{* * *} p<0.001$

and without comorbidity (aHR 2.71; 95\% CI 1.63-4.50, $p<0.001$ ).

Table 4 demonstrates the incidence and aHR of PD stratified by medication in patients with AS. Compared with patients without AS, the AS patients receiving immunosuppressant therapy had a significant increase of risk of Parkinson's disease (aHR 2.40; 95\% CI 1.26-4.56, $p<0.01$ ), followed by those without biological therapy (aHR 1.75; 95\% CI 1.38-2.23, $p<0.001$ ) and those without immunosuppressant therapy (aHR 1.70; 95\% CI 1.322.18, $p<0.001)$. In this AS cohort, 37 patients received anti-TNF-a biological therapy and none developed PD.

\section{Discussions}

In this study, we proposed AS as a risk factor for the development of PD. As per our knowledge, the association between AS and PD has rarely been investigated [17]. This was the first extensive analysis of a nationwide population database of patients with AS and PD. The result indicated that the AS patients had significantly more comorbidities, including diabetes, hypertension, hyperlipidemia, depression, coronary artery disease, head injury and chronic kidney disease than matched controls. More importantly, AS was associated with an increased risk of PD development. The crude HR of 1.92, with an aHR of 1.75, for PD development was higher in the patients with AS compared with non-AS patients. Moreover, higher risk of PD in AS cohort without comorbidity indicated AS as a potential independent risk factor for PD.

Our result agreed with a recent US claims-based study which revealed that patients with AS were shown to have significantly more comorbidities, such as hypertension, coronary artery disease, depression and dyslipidemia than matched controls. Further follow-up in that study demonstrated a higher proportion of patients developed newly diagnosed cases of hypertension, coronary artery disease, depression, osteoporosis, spinal fracture, 
Table 3 Incidence rate ratio and hazard ratio of Parkinson's disease and ankylosing spondylitis cohort to non-ankylosing spondylitis cohort

\begin{tabular}{|c|c|c|c|c|c|c|c|c|}
\hline \multirow[t]{3}{*}{ Variables } & \multicolumn{6}{|c|}{ Ankylosing spondylitis } & \multirow[t]{3}{*}{ Crude HR $(95 \% \mathrm{Cl})$} & \multirow{3}{*}{$\begin{array}{l}\text { Adjusted } \mathrm{HR}^{\dagger} \\
(95 \% \mathrm{Cl})\end{array}$} \\
\hline & \multicolumn{3}{|c|}{$\begin{array}{l}\text { No } \\
(\mathrm{N}=25,760)\end{array}$} & \multicolumn{3}{|c|}{$\begin{array}{l}\text { Yes } \\
(\mathrm{N}=6440)\end{array}$} & & \\
\hline & event & Person years & rate & event & Person years & rate & & \\
\hline \multicolumn{9}{|l|}{ Sex } \\
\hline Male & 111 & 82,421 & 1.35 & 52 & 20,957 & 2.48 & $1.85(1.33,2.57)^{* * *}$ & $1.66(1.19,2.32)^{* *}$ \\
\hline Female & 99 & 88,437 & 1.12 & 50 & 22,295 & 2.24 & $2.01(1.43,2.82)^{* * *}$ & $1.85(1.31,2.62)^{* * *}$ \\
\hline \multicolumn{9}{|l|}{ Age, years } \\
\hline$\leq 49$ & 11 & 100,196 & 0.11 & 14 & 25,575 & 0.55 & $4.99(2.26,11.0)^{* * * *}$ & $4.70(2.10,10.5)^{* * *}$ \\
\hline $50-64$ & 50 & 44,307 & 1.13 & 21 & 11,120 & 0.89 & $1.68(1.01,2.80)^{*}$ & $1.32(0.78,2.21)$ \\
\hline$\geq 65$ & 149 & 26,356 & 5.65 & 67 & 6557 & 10.2 & $1.80(1.35,2.40)^{* * * *}$ & $1.69(1.26,2.26)^{* * *}$ \\
\hline \multicolumn{9}{|c|}{ Comorbidity $^{\ddagger}$} \\
\hline No & 46 & 114,349 & 0.40 & 22 & 24,374 & 0.90 & $2.25(1.35,3.74)^{* *}$ & $2.71(1.63,4.50)^{* * *}$ \\
\hline Yes & 164 & 56,509 & 2.90 & 80 & 18,878 & 4.24 & $1.47(1.12,1.92)^{* *}$ & $1.61(1.23,2.10)^{* * *}$ \\
\hline
\end{tabular}

Rate per 1000 person-year; Crude HR, relative hazard ratio

† Model was adjusted for age and comorbidities of diabetes, hypertension, hyperlipidemia, stroke, depression, coronary artery disease, head injury, and chronic kidney disease and medication of NSAIDs

₹ Patients with any one of the comorbidities (diabetes, hypertension, hyperlipidemia, stroke, depression, coronary artery disease, head injury, chronic kidney disease and epilepsy) were classified as the comorbidity group

${ }^{*} p<0.05,{ }^{* *} p<0.01,{ }^{* * *} p<0.001$

Table 4 Incidence and adjusted hazard ratio of Parkinson's disease stratified by medication in patients with ankylosing spondylitis

\begin{tabular}{|c|c|c|c|c|c|c|}
\hline Medication exposed & $\mathbf{N}$ & Event & PY & Rate & $\begin{array}{l}\text { Crude HR } \\
(95 \% \mathrm{Cl})\end{array}$ & $\begin{array}{l}\text { Adjusted } \mathrm{HR}^{\dagger} \\
(95 \% \mathrm{Cl})\end{array}$ \\
\hline Without ankylosing spondylitis & 25,760 & 210 & 170,858 & 1.23 & 1 (Reference) & 1 (Reference) \\
\hline \multicolumn{7}{|l|}{ Ankylosing spondylitis } \\
\hline Without Immunosuppressant therapy & 5158 & 92 & 34,682 & 2.65 & $2.16(1.69,2.76)^{* * *}$ & $1.70(1.32,2.18)^{* * *}$ \\
\hline With Immunosuppressant therapy & 1282 & 10 & 8569 & 1.17 & $0.95(0.50,1.79)$ & $2.40(1.26,4.56)^{* *}$ \\
\hline Without Biological therapy & 6403 & 102 & 43,029 & 2.37 & $1.93(1.53,2.45)^{* * *}$ & $1.75(1.38,2.23)^{* * *}$ \\
\hline $\begin{array}{l}\text { With } \\
\text { Biological therapy }\end{array}$ & 37 & 0 & 223 & & - & - \\
\hline
\end{tabular}

Rate per 1000 person-year; Crude HR, relative hazard ratio

† Model was adjusted for age and comorbidities of diabetes, hypertension, hyperlipidemia, stroke, depression, coronary artery disease, head injury, and chronic kidney disease and medication of NSAIDs

${ }^{*} p<0.05,{ }^{* *} p<0.01,{ }^{* * *} p<0.001$

inflammatory bowel disease, psoriasis, and uveitis than matched controls after AS diagnosis [21].

The hypothesis that chronic inflammatory autoimmune diseases have an impact on the development of PD has been examined in several studies. Nationwide population-based researches from Taiwan and Sweden showed increased risk of PD among patients with autoimmune diseases $[16,17]$. While in another study from Denmark, no overall association was found [22]. More importantly, recent genome-wide association studies (GWAS) and pathway analyses facilitated the identification of genetic overlap, i.e. pleiotropic loci, between PD and some autoimmune diseases. The results suggested that the PDassociated loci may contribute to PD through immune defects, supporting the presence of interaction between the immune system and neurodegeneration in PD [23]. Further analyses are warranted to figure out the possible pleiotropy between AS and PD.

Given that PD risk was higher in the patients with AS, our next question was whether the increase of PD risk was due to AS treatment. To address the effect of AS treatment on the risk of PD, the incidence rate and 
aHR of PD stratified by medication in patients with AS were analyzed. Medical treatment of AS mainly consists of NSAIDs, immunosuppressants, biological agents including anti-TNF- $\alpha$ and IL-17 inhibitors. The goals of AS treatment include alleviation of pain, improvement of physical function and delay of structural damage [2426]. In this study, NSAID use was more prevalent in the AS cohort than in the non-AS cohort. Among 6440 AS patients, 1282 (19.9\%) received immunosuppressants, while $37(0.57 \%)$ underwent biological therapy.

Although some previous researches showed controversial results about the association between NSAID use and the risk of PD $[27,28]$, our result revealed that the hazard ratio for PD was significantly lower in patients taking NSAIDs compared with patients not taking (aHR 0.69). Consistent with our finding, a recent dose-response meta-analysis of NSAID use and risk of PD demonstrated that the use of non-aspirin NSAIDs was significantly associated with lower PD risk (RR:0.91; 95\% CI, 0.840.99) [29].

After adjustment for sex, age, comorbidities, and medication of NSAIDs, the AS patients treated with and without immunosuppressants, including sulfasalazine and methotrexate that are prescribed for non-axial diseases, both had higher risks of PD (aHR, 2.40 and 1.70, respectively). A seemingly paradoxical harmful effect of immunosuppressant use on the risk of PD among AS patients was observed here. However, those needed immunosuppressant treatment usually had higher disease activity and peripheral arthritis. Therefore, the increase of PD risk could be associated with stronger inflammation of the disease rather than immunosuppressant treatment. This assumption is supported by a population-based case-control study in the US examining the risk of PD in relation to use of immunosuppressants. The results suggested that sulfasalazine and methotrexate were neither contributory to nor clearly inversely associated with PD risk [30].

TNF- $\alpha$ is recognized as an important inflammatory mediator in AS and anti-TNF- $\alpha$ therapy has been applied for advanced disease. We observed that AS patients who did not receive anti-TNF- $\alpha$ biological agents had a higher risk (aHR, 1.75), while thirty-seven patients who received anti-TNF- $\alpha$ biological therapy did not develop PD. This possible protective effect of anti-TNF- $\alpha$ treatment on PD development was also observed in a RA cohort. [31].

In contrast to AS, previous studies showed reduced risk of PD in patients with RA and SLE [22, 31, 32]. The aHR for PD development was 0.65 (95\% CI, 0.58-0.73) in the RA cohort relative to the non-RA cohort [31]. On the other hand, an inverse association between SLE and the risk of subsequent PD, with aHR being 0.68 (95\% CI, 0.51-0.90), was found [32]. Our observation of AS being associated with increased risk of PD seemed contradictory, under the premise that RA and SLE both correlated inversely with risk of PD development. However, the decreased risk observed among patients with RA and SLE could be explained by protective effect of the treatment with aggressive immune-suppressive drugs over prolonged periods [31, 32]. For example, inosine monophosphate dehydrogenase inhibitors and corticosteroids, both of which are frequently used in RA and SLE but not AS, were both associated with a lower risk of PD [30]. Further research is needed to disclose the relationship and underlying mechanism between AS and PD. Prospective studies are required to determine whether specific immunosuppressants are beneficial in preventing $\mathrm{PD}$ in autoimmune diseases.

There are some potential limitations in this study. First, the database does not provide complete information on clinical, laboratory, and radiographical examinations. The AS disease activity could not be tracked. Neither could we obtain information on a family history of PD and risk factors for PD such as smoking habits, alcohol consumption, occupation, and lifestyle [33-36]. We were unable to depict further possible pathogenesis of PD in patients with AS. Second, detailed prescription records of medication including doses, timing, and durations are unavailable. Third, whether the medical instruction was fully complied by outpatients with AS cannot be confirmed. Fourth, statistical quality of a retrospective cohort study is generally lower than those from randomized trials owing to possible biases related to adjustments for confounding variables.

\section{Conclusion}

The observational studies would be leading the clinical reference value as real-world evidence and estimated the underlying risk for $\mathrm{PD}$, thus, we demonstrated that the patients with AS existed an elevated risk of subsequent PD. However, the prospective study design would be still required to assess whether different immune modulators existed benefits to PD risk in patients with autoimmune diseases. The underlying mechanism and causality need to be further investigated and clarified.

\section{Abbreviations \\ Cl: Confidence interval; aHR: Adjusted hazard ratio; ICD-9-CM: International Classification of Diseases, Ninth Revision, Clinical Modification; IRR: Incidence rate ratio; NHI: Taiwan's National Health Insurance; NHIRD: National Health Insurance Research Database; AS: Ankylosing spondylitis; PD: Parkinson's disease.}

\section{Acknowledgements}

We are thankful to all the authors for their dedication and patience throughout the study. We are also thankful to Management Office for Health Data, China Medical University Hospital, Taichung, Taiwan for the help with analyses supports. Taiwan Ministry of Health and Welfare Clinical Trial Center, China 
Medical University Hospital, Academia Sinica Taiwan, Taiwan Clinical Trial Consortium for Stroke, Tseng-Lien Lin Foundation, Taiwan Brain Disease Foundation, Katsuzo and Kiyo Aoshima Memorial Funds for the help with funding support.

\section{Author contributions}

Study concept and design: F-CY, C-HK, F-CL and T-YY.; Acquisition, analysis, or interpretation of data: C-LL.; Drafting of the manuscript: all authors.; Critical revision of the manuscript for important: $\mathrm{F}-\mathrm{CL}, \mathrm{T}-\mathrm{YY}$; Intellectual content: $\mathrm{F}-\mathrm{CL}$ and C-HK; Statistical analysis: C-LL;; Obtained funding: C-LL, C-HK, and F-CL; Administrative, technical, or material support: all authors; Study supervision: F-CY, C-HK, F-CL and T-YY.; Submission: T-YY, F-CL. All authors have read and approved the draft of manuscript.

\section{Funding}

Taiwan Ministry of Health and Welfare Clinical Trial Center, China Medical University Hospital, Academia Sinica Taiwan, Taiwan Clinical Trial Consortium for Stroke, Tseng-Lien Lin Foundation, Taiwan Brain Disease Foundation, Katsuzo and Kiyo Aoshima Memorial Funds for the help with funding support.

\section{Availability of data and materials}

All the data is underlying the present study from the National Health Insurance Research database (NHIRD) and Management Office for Health Data, China Medical University Hospital, Taichung, Taiwan. Local interested researchers or cooperators can obtain the data through formal application to the Ministry of Health and Welfare, Taiwan.

\section{Ethics approval and consent to participate}

This study was approved by the Institutional Review Board of China Medical University (CMUH-104-REC2-115).

\section{Consent for publication}

All the authors agree the manuscript in all respects for publication.

\section{Competing interests}

There are no competing interests declared by all the authors.

\section{Author details}

${ }^{1}$ Division of Rheumatology, Immunology, and Allergy, Department of Internal Medicine, Tri-Service General Hospital, National Defense Medical Center, Taipei, Taiwan. ${ }^{2}$ Department of Health Promotion and Health Education, National Defense Medical Center, Taipei, Taiwan. ${ }^{3}$ School of Medicine, China Medical University, Taichung, Taiwan. ${ }^{4}$ Management Office for Health Data, China Medical University Hospital, Taichung, Taiwan. ${ }^{5}$ Graduate Institute of Biomedical Sciences, School of Medicine, College of Medicine, China Medical University, Taichung, Taiwan. ${ }^{6}$ Department of Nuclear Medicine and PET Center, China Medical University Hospital, Taichung, Taiwan. ${ }^{7}$ Department of Bioinformatics and Medical Engineering, Asia University, Taichung, Taiwan. ${ }^{8}$ Center of Augmented Intelligence in Healthcare, China Medical University Hospital, Taichung, Taiwan. ${ }^{9}$ Graduate Institute of Chinese Medicine, China Medical University, Taichung, Taiwan. ${ }^{10}$ Molecular and Genomic Epidemiology Center and Department of Medical Research, China Medical University Hospital, Taichung, Taiwan. ${ }^{11}$ Center for General Education \& Master Program of Digital Health Innovation, College of Humanities and Sciences, China Medical University, Taichung, Taiwan. ${ }^{12}$ Department of Medical Laboratory and Biotechnology, Asia University, Taichung, Taiwan.

Received: 16 September 2020 Accepted: 20 November 2020 Published online: 30 November 2020

\section{References}

1. Zhu W, He X, Cheng K, Zhang L, Chen D, Wang X, Qiu G, Cao X, Weng X. Ankylosing spondylitis: etiology, pathogenesis, and treatments. Bone Res. 2019;7:22.

2. Liu W, Wu YH, Zhang L, Liu XY, Xue B, Wang Y, Liu B, Jiang Q, Kwang HW, Wu DJ. Elevated serum levels of IL-6 and IL-17 may associate with the development of ankylosing spondylitis. Int J Clin Exp Med. 2015;8:17362-76.
3. Venken K, Jacques P, Mortier C, Labadia ME, Decruy T, Coudenys J, Hoyt K, Wayne AL, Hughes R, Turner M, Van Gassen S, Martens L, Smith D, Harcken C, Wahle J, Wang CT, Verheugen E, Schryvers N, Varkas G, Cypers H, Wittoek R, Piette Y, Gyselbrecht L, Van Calenbergh S, Van den Bosch F, Saeys Y, Nabozny G, Elewaut D. RORgammat inhibition selectively targets IL-17 producing iNKT and gammadelta-T cells enriched in Spondyloarthritis patients. Nat Commun. 2019;10:9.

4. El Maghraoui A. Extra-articular manifestations of ankylosing spondylitis: prevalence, characteristics and therapeutic implications. Eur J Intern Med. 2011;22:554-60.

5. Jang HD, Park JS, Kim DW, Han K, Shin BJ, Lee JC, Choi SW, Suh SW, Yang JH, Park SY, Cho WJ, Hong JY. Relationship between dementia and ankylosing spondylitis: a nationwide, population-based, retrospective longitudinal cohort study. PLOS ONE. 2019;14:e0210335.

6. Lin CW, Huang YP, Chiu YH, Ho YT, Pan SL. Increased risk of ischemic stroke in young patients with ankylosing spondylitis: a population-based longitudinal follow-up study. PLoS ONE. 2014;9:e94027.

7. Park JS, Jang HD, Hong JY, Park YS, Han K, Suh SW, Park SY, Kim BT. Impact of ankylosing spondylitis on depression: a nationwide cohort study. Sci Rep. 2019;9:6736.

8. Barzilai A, Melamed E. Molecular mechanisms of selective dopaminergic neuronal death in Parkinson's disease. Trends Mol Med. 2003;9:126-32.

9. Caggiu E, Arru G, Hosseini S, Niegowska M, Sechi G, Zarbo IR, Sechi LA. Inflammation, infectious triggers, and Parkinson's disease. Front Neurol. 2019;10:122.

10. Koziorowski D, Tomasiuk R, Szlufik S, Friedman A. Inflammatory cytokines and NT-proCNP in Parkinson's disease patients. Cytokine. 2012;60:762-6.

11. Jimenez-Jimenez FJ, Alonso-Navarro H, Garcia-Martin E, Agundez JA. Cerebrospinal fluid biochemical studies in patients with Parkinson's disease: toward a potential search for biomarkers for this disease. Front Cell Neurosci. 2014:8:369.

12. Vesely B, Dufek M, Thon V, Brozman M, Kiralova S, Halaszova T, Koritakova E, Rektor I. Interleukin 6 and complement serum level study in Parkinson's disease. J Neural Transm (Vienna). 2018;125:875-81.

13. Pereira JR, Santos LVD, Santos RMS, Campos ALF, Pimenta AL, de Oliveira MS, Bacheti GG, Rocha NP, Teixeira AL, Christo PP, Scalzo PL. IL-6 serum levels are elevated in Parkinson's disease patients with fatigue compared to patients without fatigue. J Neurol Sci. 2016;370:153-6.

14. Green HF, Khosousi S, Svenningsson P. Plasma IL-6 and IL-17A Correlate With Severity Of Motor And Non-Motor Symptoms in Parkinson's disease. J Parkinsons Dis. 2019;9:705-9.

15. Schroder JB, Pawlowski M, Meyer Zu Horste G, Gross CC, Wiendl H, Meuth SG, Ruck T, Warnecke T. Immune cell activation in the cerebrospinal fluid of patients With Parkinson's disease. Front Neurol. 2018;9:1081.

16. Chang CC, Lin TM, Chang YS, Chen WS, Sheu JJ, Chen YH, Chen JH. Autoimmune rheumatic diseases and the risk of Parkinson disease: a nationwide population-based cohort study in Taiwan. Ann Med. 2018;50:83-90.

17. Li X, Sundquist J, Sundquist K. Subsequent risks of Parkinson disease in patients with autoimmune and related disorders: a nationwide epidemiological study from Sweden. Neurodegener Dis. 2012;10:277-84.

18. Wu SH, Chuang E, Chuang TY, Lin CL, Lin MC, Yen DJ, Kao CH. A nationwide population-based cohort study of migraine and organic-psychogenic erectile dysfunction. Medicine (Baltimore). 2016;95:e3065.

19. Kao CC, Lin CL, Huang WY, Cha TL, Lin TY, Shen CH, Kao CH. Association between inflammatory bowel disease and erectile dysfunction: a nationwide population-based study. Inflamm Bowel Dis. 2016;22:1065-70.

20. Chen $\mathrm{CH}$, Lin $\mathrm{CL}$, Kao CH. Gastroesophageal reflux disease with proton pump inhibitor use is associated with an increased risk of osteoporosis: a nationwide population-based analysis. Osteoporos Int. 2016;27:2117-26.

21. Walsh JA, Song X, Kim G, Park Y. Evaluation of the comorbidity burden in patients with ankylosing spondylitis using a large US administrative claims data set. Clin Rheumatol. 2018;37:1869-78.

22. Rugbjerg K, Friis S, Ritz B, Schernhammer ES, Korbo L, Olsen JH. Autoimmune disease and risk for Parkinson disease: a population-based casecontrol study. Neurology. 2009;73:1462-8.

23. Witoelar A, Jansen IE, Wang Y, Desikan RS, Gibbs JR, Blauwendraat C Thompson WK, Hernandez DG, Djurovic S, Schork AJ, Bettella F, Ellinghaus D, Franke A, Lie BA, McEvoy LK, Karlsen TH, Lesage S, Morris HR, Brice A, Wood NW, Heutink P, Hardy J, Singleton AB, Dale AM, Gasser T, Andreassen OA, Sharma M. International Parkinson's Disease Genomics Consortium NABEC and United Kingdom Brain Expression Consortium I. 
Genome-wide pleiotropy between parkinson disease and autoimmune diseases. JAMA Neurol. 2017;74:780-92.

24. Baeten D, Sieper J, Braun J, Baraliakos X, Dougados M, Emery P, Deodhar A, Porter B, Martin R, Andersson M, Mpofu S, Richards HB, Group MS and Group MS. Secukinumab, an interleukin-17A inhibitor, in ankylosing spondylitis. N Engl J Med. 2015;373:2534-48.

25. Ward MM, Deodhar A, Akl EA, Lui A, Ermann J, Gensler LS, Smith JA, Borenstein D, Hiratzka J, Weiss PF, Inman RD, Majithia V, Haroon N, Maksymowych WP, Joyce J, Clark BM, Colbert RA, Figgie MP, Hallegua DS, Prete PE, Rosenbaum JT, Stebulis JA, van den Bosch F, Yu DT, Miller AS, Reveille JD, Caplan L. American College of Rheumatology/Spondylitis Association of America/Spondyloarthritis Research and Treatment Network 2015 recommendations for the treatment of ankylosing spondylitis and nonradiographic axial spondyloarthritis. Arthritis Rheumatol. 2016;68:282-98.

26. Moon KH, Kim YT. Medical treatment of ankylosing spondylitis. Hip Pelvis. 2014;26:129-35

27. Becker C, Jick SS, Meier CR. NSAID use and risk of Parkinson disease: a population-based case-control study. Eur J Neurol. 2011;18:1336-42.

28. Poly TN, Islam MMR, Yang HC, Li YJ. Non-steroidal anti-inflammatory drugs and risk of Parkinson's disease in the elderly population: a meta-analysis. Eur J Clin Pharmacol. 2019;75:99-108.

29. Ren L, Yi J, Yang J, Li P, Cheng X, Mao P. Nonsteroidal anti-inflammatory drugs use and risk of Parkinson disease: A dose-response meta-analysis. Medicine (Baltimore). 2018;97:e12172.

30. Racette BA, Gross A, Vouri SM, Camacho-Soto A, Willis AW, Searles NS. Immunosuppressants and risk of Parkinson disease. Ann Clin Transl Neurol. 2018:5:870-5.

31. Sung YF, Liu FC, Lin CC, Lee JT, Yang FC, Chou YC, Lin CL, Kao CH, Lo HY, Yang TY. Reduced risk of Parkinson disease in patients with rheumatoid arthritis: a nationwide population-based study. Mayo Clin Proc. 2016;91:1346-53.

32. Liu FC, Huang WY, Lin TY, Shen $\mathrm{CH}$, Chou YC, Lin CL, Lin KT, Kao CH. Inverse association of Parkinson disease with systemic lupus erythematosus: a nationwide population-based study. Medicine (Baltimore) 2015;94:e2097.

33. Frigerio R, Elbaz A, Sanft KR, Peterson BJ, Bower JH, Ahlskog JE, Grossardt BR, de Andrade M, Maraganore DM, Rocca WA. Education and occupations preceding Parkinson disease: a population-based case-control study. Neurology. 2005;65:1575-83.

34. Hancock DB, Martin ER, Stajich JM, Jewett R, Stacy MA, Scott BL, Vance JM, Scott WK. Smoking, caffeine, and nonsteroidal anti-inflammatory drugs in families with Parkinson disease. Arch Neurol. 2007;64:576-80.

35. Saaksjarvi K, Knekt P, Rissanen H, Laaksonen MA, Reunanen A, Mannisto S. Prospective study of coffee consumption and risk of Parkinson's disease. Eur J Clin Nutr. 2008;62:908-15.

36. van der Mark M, Nijssen PC, Vlaanderen J, Huss A, Mulleners WM, Sas AM, van Laar T, Kromhout H, Vermeulen R. A case-control study of the protective effect of alcohol, coffee, and cigarette consumption on Parkinson disease risk: time-since-cessation modifies the effect of tobacco smoking. PLOS ONE. 2014;9:e95297.

\section{Publisher's Note}

Springer Nature remains neutral with regard to jurisdictional claims in published maps and institutional affiliations.
Ready to submit your research? Choose BMC and benefit from:

- fast, convenient online submission

- thorough peer review by experienced researchers in your field

- rapid publication on acceptance

- support for research data, including large and complex data types

- gold Open Access which fosters wider collaboration and increased citations

- maximum visibility for your research: over $100 \mathrm{M}$ website views per year

At BMC, research is always in progress.

Learn more biomedcentral.com/submissions 